\title{
"Maybe I Made Up the Whole Thing": Placebos and Patients' Experiences in a Randomized Controlled Trial
}

\author{
Ted J. Kaptchuk · Jessica Shaw - Catherine E. Kerr • \\ Lisa A. Conboy · John M. Kelley • Thomas J. Csordas • \\ Anthony J. Lembo · Eric E. Jacobson
}

Published online: 14 July 2009

(C) The Author(s) 2009. This article is published with open access at Springerlink.com

\begin{abstract}
Patients in the placebo arms of randomized controlled trials (RCT) often experience positive changes from baseline. While multiple theories concerning such "placebo effects" exist, peculiarly, none has been informed by actual interviews of patients undergoing placebo treatment. Here, we report on a qualitative study $(n=27)$ embedded within a RCT $(n=262)$ in patients with irritable bowel syndrome. Besides identical placebo acupuncture treatment in the RCT, the qualitative study patients also received an additional set of interviews at the beginning,
\end{abstract}

T.K., E.J., L.C., C.K., J.K. and A.L. initiated the RCT and obtained funding. E.J., T.K., C.K. and L.C. designed the qualitative study. Interviews were performed by E.J., and L.C., T.K., J.S., E.J., L.C., C.K., T.C., A.L. and J.K. performed the initial analysis and interpretation. J.S. devised the coding framework in consultation with all authors. T.K., E.J. and J.S. wrote the first draft. All authors commented on subsequent drafts. T.K. is the guarantor and accepts full responsibility for the conduct of the study and the contents of the paper.

T. J. Kaptchuk $(\bowtie) \cdot$ J. Shaw · C. E. Kerr · L. A. Conboy Osher Research Center, Harvard Medical School, 401 Park Drive, Boston, MA 02215, USA e-mail: ted_kaptchuk@hms.harvard.edu

T. J. Kaptchuk · A. J. Lembo

Beth Israel Deaconess Medical Center, Harvard Medical School, Boston, MA 02215, USA

J. M. Kelley

Endicott College, Beverly, MA 01915, USA

J. M. Kelley

Harvard Medical School, Boston, MA 02215, USA

T. J. Csordas

Department of Anthropology, University of California, San Diego, La Jolla, CA 92093, USA

E. E. Jacobson

Department of Global Health and Social Medicine, Harvard Medical School, Boston, MA 02215, USA 
midpoint, and end of the trial. Interviews of the 12 qualitative subjects who underwent and completed placebo treatment were transcribed. We found that patients (1) were persistently concerned with whether they were receiving placebo or genuine treatment; (2) almost never endorsed "expectation" of improvement but spoke of "hope" instead and frequently reported despair; (3) almost all reported improvement ranging from dramatic psychosocial changes to unambiguous, progressive symptom improvement to tentative impressions of benefit; and (4) often worried whether their improvement was due to normal fluctuations or placebo effects. The placebo treatment was a problematic perturbation that provided an opportunity to reconstruct the experiences of the fluctuations of their illness and how it disrupted their everyday life. Immersion in this RCT was a co-mingling of enactment, embodiment and interpretation involving ritual performance and evocative symbols, shifts in bodily sensations, symptoms, mood, daily life behaviors, and social interactions, all accompanied by self-scrutiny and re-appraisal. The placebo effect involved a spectrum of factors and any single theory of placebo-e.g. expectancy, hope, conditioning, anxiety reduction, report bias, symbolic work, narrative and embodiment_-provides an inadequate model to explain its salubrious benefits.

Keywords Placebo effect · Placebo controls · Randomized controlled trials · Placebo · Acupuncture - Irritable bowel syndrome · Patient-physician relationship · Expectancy · Conditioning · Anxiety reduction - Report bias · Embodiment . Ritual

\section{Introduction}

Biomedicine created the apparatus of the placebo-controlled randomized clinical trial (RCT) so that highly variable human clinical conditions can be studied with the mathematical precision of the laboratory experiment. Such trials provide the evidence for claiming that biomedical therapies are scientific and actually provide more than the effects of participation in a healing ritual (Kaptchuk 1998a). Operationally, the RCT separates the effects of the ritual of treatment (conveniently segregated in the placebo controls) from the presumptively objective effects of pharmacological medications or physiologically active procedures (Kaptchuk 1998b; Kaptchuk et al. 2009). For biomedicine, the placebo effect demarcates legitimate from illegitimate healing (Sullivan 1993; Kaptchuk 2003).

Yet patients frequently report relief in the placebo-control arms of RCTs, thereby creating a conundrum for the centrality of pharmacological mechanisms in biomedicine (Comaroff 1976). While some of the amelioration observed in placebo groups is undoubtedly related to the natural course of an illness, spontaneous remission and regression to the mean, recent sophisticated laboratory studies of placebo treatment indicate the existence of a genuine short-term placebo effect beyond natural history. These experiments have revealed both behavioral changes and quantifiable objective changes in neurotransmitters, hormones, immune regulators and regionally specific brain activity that could influence peripheral disease processes through plausible physiological mechanisms (Benedetti et al. 
2005; Kong et al. 2007; Benedetti 2008; Enck et al. 2008). How these laboratory effects, often obtained on health normal volunteers, in artificial circumstances, apply to various clinical conditions over longer periods of time remains unclear (Kamper et al. 2008; Hróbjartson and Gotzsche 2001).

Within biomedicine (and also psychology), the two dominant conceptual models for placebo effects are expectancy and classical conditioning. Expectancy posits that the key factor involved in the placebo effect is cognitive, that is, what the patient thinks or expects to happen as a result of treatment (Kirsch 1985, 2004). The "strength" of an expectation is usually regarded as measurable and stable, and the basis for predicting definable outcomes. Discussions of what might mediate expectancy to placebo treatment invoke notions of trust, beliefs, faith or the patienthealer relationship (Kirsch 1997). That expectancies can lead to symptom improvement and that these improvements have physiological correlates has been supported by recent laboratory experiments that administer noxious stimuli (e.g., pain) and then provide strong expectancies plus placebo treatment and observe symptom improvement (e.g., analgesia) along with measurable biochemical (e.g., endorphins, dopamine) and brain neuroanatomical correlates (e.g., rostral anterior cingulated cortex, right anterior insula) (Zubieta et al. 2005; Kong et al. 2006; Scott et al. 2007; Petrovic et al. 2002).

Other scientists argue that placebo responses are better understood using a model of classical conditioning or "stimulation substitution," emphasizing a primarily automatic unconscious process capable of eliciting health benefits. Classical conditioning posits that a previously experienced response to active medication (unconditioned response) plus the administration of a pill (conditioned stimulus) causes a subsequent positive response from the provision of a dummy pill alone (conditioned response) in a manner exemplified by Pavlov's dogs (Turkkan 1989; Ader 1997). Well-designed laboratory experiments on both animals and humans had demonstrated that classical conditioning influences immunological, endocrinal, intestinal and other bodily functions (Pacheoco-Lopez et al. 2006).

Some have argued that the expectancy and conditioned response models are not mutually exclusive, that both involve learned behaviors, that conditioning can lead to conscious expectations and that expectation can lead to stimulus substitution responses (Steward-Williams and Podd 2004; Klinger et al. 2007). Nonetheless, several experiments have demonstrated that expectation and conditioning are distinct, and can operate through unique biochemical mechanisms, and that these pathways can be combined to produce greater pain relief than either component alone (e.g., Amanzio and Benedetti 1999; Colloca et al. 2008).

Though receiving less attention in recent years, anxiety reduction has also been implicated as contributing to placebo responses (McGlashan et al. 1969; Shapiro et al. 1973; Evans 1974; Price et al. 1999; Staats et al. 2001; Price and Soerensen 2002; Geers et al. 2005; Vase et al. 2005). The essential idea is that reduced anxiety encourages the experience and interpretation of ambiguous sensations to be perceived as less threatening, dangerous and disruptive. Anxiety, to use "signal detection theory" language, lowers the participant's "response criterion" so that fewer sensations are experienced or registered as noxious (Allan and Siegel 2002). What would have originally been a menacing or discomforting signal and a 
"somatic focus" of concern is experienced as more benign, less threatening, unimportant or just not worthy of much attention (Lundh 1987; Geers et al. 2006). Very recently a flurry of studies have found neurochemical (e.g., cholecystokinin) and neuroanatomical (e.g., left hippocampus signal increases) correlates of nocebo treatments (i.e., placebo treatments administered in a context of anticipatory anxiety) (Benedetti et al. 2006; Kong et al. 2008; cf. Petrovic et al. 2005).

Biomedicine has also proposed several other contributing factors to the placebo response in RCTs. Report bias (the tendency of subjects to report what they think the researcher wants them to report; what psychologists call "demand characteristics") is sometimes considered an important dimension of the placebo response (Crowne and Marlowe 1960; Orne 1962; Knight et al. 1986; Cleophas 1995). Another factor may be distortion in memory. Psychophysics has pointed out that recalled discomfort tends to be of a higher magnitude than the same discomfort measured contemporaneously (Price et al. 1999; Rainville et al. 2004). And, inevitably, genetic polymorphisms have been implicated (Furmark et al. 2008). Given the various contributing factors believed to be involved and the different possible biological pathways uncovered in laboratories, theorists have begun to abandon unitary theories of a placebo effect and discuss the placebo effect as a spectrum of responses (Benedetti 2009; Kaptchuk 2008).

In contrast to biomedical perspectives, medical anthropologists often adopt a constructionist view, that is, that the individual's experience of "placebo treatment" and its effects involves an active synthesis of factors other than those included in the purely cognitivist or behaviorist models, for example, personal history, evaluations, and the organization of the "self" and its narrative trajectory. Fundamental to all these approaches is a distinction between "illness" and "healing" as terms for referring to subjective and socioculturally constructed aspects of medical experience, and "disease" and "cure," which refer to biomedically defined biological conditions (Eisenberg 1977, 1983). Some anthropologists have suggested that the "placebo response" may be better conceptualized as a "culturogenic" factor (Hahn and Kleinman 1983; Kleinman 1973) or as a "meaning response" (Moerman 2002; Moerman and Jonas 2002). These reflect longer-standing anthropological hypotheses that therapeutically induced changes in the "meaning" that patients ascribe to their illness, self and social relations may contribute to healing (Frank 1961; LéviStrauss 1963; Tambiah 1977; Moerman 1979; Dow 1986; Csordas 1994). The factors that these theories identify as contributing to efficacious healing include culturally powerful metaphors and symbols (especially those that refer to or directly contact the patient's body), the healer's prestige, social interactions with relatives and community members in the course of preparations and performance of ritual and the contributions of gesture, recitation, costume and iconography to the overall "performative efficacy" of the ritual. Also, other factors that vary from one patient to another include personal history, cognitive models, favored narratives of the "self" and cultural values.

An additional explanation for placebo effects that is shared by both biomedicine and anthropological perspectives and is usually described as the patient-physician or patient-healer relationship (e.g., Adler and Hammett 1973; Kleinman 1988; Stewart 1995; Brody 1997; Di Blasi et al. 2001). The clinical encounter embeds a 
broad array of potentially placebogenic components, including cognitive factors (e.g., diagnosis, confidence, explanatory models, treatment plans, sanctioning of sick role), emotional factors (e.g., empathic witnessing, compassion, reassurance, respect, active listening, collaborative trust, opportunity for catharsis), practitioner behaviorial factors (e.g., head-nodding, bodily postures, eye gaze and thoughtful silence), patient behaviorial factors (e.g., requesting relief, complying with healing regime), sensory factors (e.g., touch, smells, sounds, bodily feelings), aesthetic factors (e.g., stylized and dramatic movements and gestures, evocative weaving of microlevel ritual details with macrolevel meta-concerns, linkage of hope with persuasive rationale) and symbolic processes (e.g., authoritative healers, needles, pills, diplomas, healing environments). Many of these components overlap with other proposed mechanisms discussed earlier. In fact, most of the earlier-proposed mechanisms clearly would need the "activation" of the patient-healer encounter and could not exist independent of it.

Our team is unfamiliar with any concrete implementation of qualitative methodologies or anthropological analyses to prospectively investigate the experiences of patients who are undergoing placebo treatment in the context of an RCT. As a preliminary step toward filling this lacuna, our team opted to embed a qualitative study within a larger RCT to learn more about the experiences of patients undergoing placebo treatment. In this article we report a portion of our findings from the qualitative interview data obtained in that study. The questions informing this part of our analysis were: What do patients experience, think and feel when undergoing a treatment that they have been told may be a placebo? What are patients' expectations for improvement in a placebo-controlled clinical trial? How do patients describe perceived improvements while under placebo treatment? And how do patients reconstruct their illness and potential healing as they undergo the experience of the RCT? Elsewhere, we will report on other aspects of patients' experiences including issues of embodiment, explanatory models, narrativity and changing interpretations of the social support available to them.

\section{Methods: The Parent Quantitative Study}

Using standard RCT procedures, the parent study was designed to quantitatively investigate placebo effects in patients with irritable bowel syndrome (IBS) (Kaptchuk et al. 2008). The study took place between December 2004 and April 2006. We selected IBS as a model illness for this study because previous RCTs had shown a large positive response in placebo groups (Patel et al. 2005). Biomedicine defines IBS as a functional gastrointestinal disorder characterized by chronic or recurrent abdominal pain or discomfort, usually in the lower abdomen, which is associated with disturbed bowel function and feelings of abdominal distention and bloating (Longstreth et al. 2006). IBS appears to involve alterations in intestinal motility, visceral hypersensitivity and abnormalities in the brain-gut axis that processes visceral information. Anxiety disorders are higher in IBS patients compared to the general population (Lydiard 2001; Botha and Libby 2006) and psychosocial distress both exacerbates and is a consequence of IBS (Drossman et al. 
1999). Because there is no physiological marker specific for IBS, outcome measures in clinical trials are based on validated scales of patient reports.

Our qualitative study was embedded in a 6-week, three-arm, single-blind RCT ( $n=262$ ) designed to test the hypothesis that the magnitude of the placebo response could be systematically augmented by progressively combining three components of the response to placebo: (1) the patients' experience of observation/ assessment, (2) the performance of a therapeutic ritual (placebo treatment) and (3) an augmented patient-practitioner relationship - in a manner resembling a graded escalation of "dose" (analogous to dose dependency). For the first 3 weeks, patients were randomized to either (1) no treatment waiting list, (2) biweekly "treatment" with placebo acupuncture within the context of a "limited" practitioner interaction or (3) biweekly "treatment" with placebo acupuncture within the context of an "augmented' patient-practitioner relationship. After the first 3 weeks, half of the patients on placebo treatment were rerandomized to continue on placebo treatment for an additional 3 weeks and the other half were assigned to 3 weeks of genuine acupuncture. The main outcome of the trial was in the first 3 weeks; the additional 3 weeks of placebo treatment was considered a follow-up. (The genuine acupuncture comparison was considered an independent secondary nested study and not included in the primary RCT analysis or this report; Lembo et al. 2009.)

In the "limited" treatment group the acupuncturists explained that the RCT was a "scientific study" and they had been "instructed not to converse with patients." They also administered placebo acupuncture. This was as close to a treatment without a therapeutic interaction as possible. In the "augmented" treatment group, besides the sham acupuncture, practitioners reviewed IBS symptoms and performed a psychosocial intake in the context of warmth, active listening, empathy and communication of confidence. Placebo acupuncture was adopted because evidence suggests that acupuncture, like many other procedures and devices, has an unusually high placebo effect (Kaptchuk et al. 2000, 2006). We used a validated placebo acupuncture device that is indistinguishable from acupuncture (Streitberger and Kleinhenz 1998). The shaft of the sham acupuncture device does not actually pierce the skin but creates the illusion of doing so by retracting into a hollow handle like a magic sword. This device makes distinguishing the touch of a blunt needle tip from real penetration practically impossible.

All participants were naive to acupuncture and were told both verbally and in written informed consent that they had a $50 \%$ chance of receiving placebo or genuine treatment. Patients were also told that the study was intended to compare acupuncture and sham acupuncture, and were not told that the RCT's primary goal was to study placebo effects. They were informed about the primary goal after the completion of the entire experiment. The ethics committee of the Beth Israel Deaconess Medical Center and Harvard Medical School approved the RCT as well as the embedded qualitative study. Details of the design, ethics and results of the quantitative experiment are reported elsewhere (Kaptchuk et al. 2008; Kelley et al. 2009; Conboy et al. 2006).

The RCT produced quantitative biomedical "facts" about the placebo effect (Kaptchuk et al. 2008). The outcome measures confirmed our hypothesis that the three arms behaved in a "dose-response" manner: waitlist $<$ limited $<$ augmented. 
The placebo effects both between the groups and from baseline were both statistically and clinically significant and showed that placebo effects could be manipulated in a manner analogous to dose escalation. The arm with the augmented patient-practitioner relationship reported symptom improvement on a magnitude as great as any medication approved for IBS by the FDA.

\section{Qualitative Study Methods: Setting, Sampling, Interviews and Analysis}

In addition to the quantitative RCT, an additional 27 patients (9 in each arm) were randomly assigned to participate qualitative interviews at baseline, 3 and 6 weeks. This paper reports on the qualitative subjects who were assigned to either placebo condition ("limited" or "augmented") for the first 3 weeks and the half of those subjects who continued for an additional 3 weeks of placebo treatment. Of the 18 qualitative subjects who were assigned to either the augmented or the limited placebo treatment arms, 13 completed the study, although one did not cooperate with the interview process. This report is based on interviews conducted at baseline (12 patients), 3 weeks (12 patients) and 6 weeks (6 patients) with subjects who were randomized to continue on placebo treatment.

The 12 qualitative subjects were aged between 23 and 65 years, with an average of 43 years ( $\mathrm{SD}=17$ years). Seven were women and five were men. Most patients reported modest to dramatic improvement in their IBS symptoms. (Of the two who did not, one reported improvement at 3 weeks and then returned to her normal situation at 6 weeks.) Six patients were in the "limited" patient-practitioner relationship placebo group, and six in the "augmented" interaction group.

Although the quantitative measures of IBS symptom severity found a significant difference between the augmented and the limited treatment groups, a careful examination of the qualitative interviews found little obvious difference between the accounts given by the two groups. With a few exceptions, which are noted below, the same kinds of words, experiences and perceptions seem to mark the testimonies of both groups. Our qualitative interviews themselves may have served as a supplemental patient-practitioner relationship for subjects assigned to the limited arm and thereby obscured what might otherwise have been significant differences between their accounts and those of the augmented subjects. The interviews seemed to act as a second level of augmented clinical interaction. In fact, the qualitative patients in the limited group had significantly more improvement than those patients who were only in the limited quantitative study. Despite this difference, because the interviews from the augmented and limited were not distinguishable, the two placebo groups are mostly not distinguished in this analysis, except in a few instances when a differential trend seems to exist. Also, except for the few instances noted, no characteristic of the qualitative interviews distinguished those who only completed the 3-week placebo treatment from those who went on to complete a 6-week course of treatment.

Three semistructured agenda-guided, open-ended interviews were conducted with each patient. The agendas, which were slightly different for the interviews at baseline, midpoint and endpoint of the trial, consisted of questions focusing on 
specific themes-for example, what it was like to be in a placebo-controlled trial and what changes were expected from the treatments-and also provided probes designed to elicit descriptions of somatosensory experience, explanatory models, images/metaphors and narrative accounts - in each thematic area. Interviews lasted between 15 and 45 min and took place in rooms nearby those in which treatments for the RCT were performed; that is, the general environment was that of a research ward in a large teaching hospital. All sessions were audiotaped and transcribed.

A medical anthropologist (E.J.) conducted most of the interviews. However, because of scheduling conflicts, three patients were interviewed by a backup sociologist (L.C.). Patients had the same interviewer for all three sessions with one exception, again due to schedule conflicts. The interviewers only saw the patients during the interviews and were not otherwise engaged with them.

All members of our core qualitative team (T.K., E.J., J.S., L.C., C.K.) participated in developing a priori coding categories on the basis of theoretical interests, and these were supplemented and reworked during the early phase of coding. In general, the final scheme allowed for coding not only by theme, for example, feelings/thoughts about their treatment, expectation and experience of improvement, but also by forms of discourse, for example, explanation, narration, imagery and metaphor. Ultimately all of the investigators developed their own variant of the coding scheme, depending on their particular research interests. For this paper, two investigators (T.K. and J.S.) coded the interviews and met regularly to compare coding and resolve differences. Other investigators also gave advice and feedback. Other team members will report their own research hypotheses and findings elsewhere. Below we report on the main themes that emerged concerning patients' experiences considering the possibility they may receive placebos, their expectations and reasons for joining the RCT and their monitoring and interpretation of changes in their illness while being treated with placebo. All names are pseudonyms.

\section{Outcomes: Thinking about Placebo}

\section{Deliberating Treatment: "I'm Anxious...to Find Out...Whether I'm on Placebo"}

Most theoretical analyses of placebo effects assume that it is easy for patients to have a positive expectation of the novel therapy and to overlook or neglect the possibility that they may be receiving placebo, even though that possibility presumably was explained in the informed consent. Contrary to this assumption, when asked directly, our patients consistently expressed their awareness that they might be receiving placebo treatment, and persistently attempted to resolve their uncertainty by heightened surveillance, investigation and interpretation of various aspects of their experience.

After the patients had begun to receive treatments at interviews 2 and 3, our interview team asked "Do you think you're receiving the real acupuncture or the placebo acupuncture?" Patients consistently expressed a deep interest in this 
question (and our questioning may have further stimulated their interest). Certainly in our interviews, all were highly engaged in questioning the "realness" of their treatment and frequently referred to the intervention in words similar to Emily's: "these treatments-whether they're real or fake..." As all were naïve to acupuncture, many had questions about what "fake" acupuncture might entail. While most patients experienced the sensation of needle penetration with the placebo device - the placebo needle provided a sensory experience that patients always interpreted as penetration - they continued to question whether they might, nevertheless, be receiving placebo. They often pondered and carefully analyzed the situation. For example, Kate deliberated:

Mmm ... well that's another thing I've been speculating about, you know. I don't know if the real acupuncture is just in different spots because I know I'm having needles put in, and I don't know if the placebo acupuncture is just in different spots that are, perhaps less effective. I have absolutely no idea if ... it [is] just a less-effective location, than not. I don't know if it's real or placebo.

Abigail had a similar issue: "All right, I'm guessing ... my guess is that I'm getting the real treatment... But maybe it is [that in] a real treatment they're inserted more. I don't know." And David noted: "I'm anxious at some point to find out, when it's appropriate, whether I'm on the placebo or [if I] am in the other one. And if I'm in the placebo, I'll be disappointed, but I will understand that it's part of the program." Francis proposed another theory of placebo treatment this way:

I don't even know if the placebo is one [where the acupuncture] ... just hits relaxation things or anything, but that was one of my theories ... that maybe the placebo isn't specifically for IBS symptoms, but for relaxation to see if relaxation affects how the IBS symptoms are.

\section{Outcomes: Discourses of Anticipation and Joining the RCT}

The transcripts reveal several distinct variations of discourse on patients' anticipation for the outcome of the trial. These revolved around distinctions among "expectation," "desperation" and "hope."

\section{Expectations and Desperations: "I Haven't Anything to Lose"}

As mentioned earlier, an important theory of placebo response is that positive expectation activates symptom improvement. Contrary to this, ten of our patients expressed more or less neutral expectations. For example, Kate said: "I can't say I'm expecting that much, but I think if something did happen, it'd be a pleasant surprise.... It is worth a shot because otherwise, if nothing else, I'm no worse off than I am today, you know.... I haven't anything to lose." And Abigail repeated a bleak chorus with: "I guess it's a long shot, I don't know. I have no clue." Fred summarizes this sense of neutral expectations by saying: "I really have no expectations whatsoever, you know." 
A history of multiple therapeutic failures, common in the treatment histories of IBS patients, probably tempered any positive expectations. Despair lurks in these dialogues. Barbara lamented:

You get to a point where you're so desperate, you'll try anything. People told me if I wore pink everyday, I would do it. I really would try anything. If they told me that I should drink saltwater, I would try it.... I would like it to work. Um. If it doesn't work, well, I tried, so I didn't really lose.

Greta repeats similar ideas: "I mean I'm desperate. I'll try anything. I'll just-I'll try just about anything." Deb continued the same sentiment: "I'd had a particularly bad year and I wasn't getting any response from the fiber, you know, and I wasn't taking Zelnorm or doing anything else, so I thought, 'You know what, this can't hurt." And Alan passively states: "Not really. I don't have any particular [expectations], no. I just want to come for the experience and see what happens."

Only two participants expressed positive expectations, if still a bit cautiously. Emily simply remarked, "I think it will help me reduce some of the symptoms," and Ben thought, "I think it's gonna work better than the Celantathral [an experimental drug that was ineffective for the patient] ... and I'm gonna be okay because I'm not gonna be one of the guys getting the placebo. And I gotta think that way, and if I am, and if I am getting the placebo and, you know, and who knows?"

\section{Hope: "I Mean, I Don't Expect Anything. I Hope that it Will Help"}

If positive "expectations" were in short supply for our participants, something labeled "hope" was spontaneously raised as a contrast to positive expectation by 7 of our 12 patients. Many patients seemed to distinguish between what they could "expect" (likelihood of improvement or failure) and what they could "hope" (desire for improvement) or not "hope" for (continued therapeutic failure).

When the interviewer asked Deb, "And what do you expect to get from the acupuncture treatments?" her response was, "I don't expect anything. I hope that it will help me." Abigail reflected in a similar fashion: "Hey, you know if, maybe there's some treatment that can help me. But I have no idea. I'm just hopeful." Francis echoed: "I'm hoping the acupuncture will work."

Even after experiencing considerable improvement after 3 weeks of treatment, when asked, "Do you have an expectation of what will happen from this point?" Deb seems to protect herself from disappointment: "That's what I'm curious about. Because now I'm feeling so good, and I'm at this nice point. I don't know now if my body [has] made a sufficient adjustment. I'm hoping that I've kind of made a change."

\section{Outcomes: Accounts of Change}

In each interview, participants were asked to describe any changes they ascribed to their involvement with the trial. With the exception of one person, all had meticulously and carefully scrutinized their symptoms, their behavior and their lives 
for signs of change. Often their responses were embedded in the details of their lifeworlds. Although our sample was small, we identified several rhetorics and idioms of change. Some patients described an uneven course of improvement, while others reported a steady progression. Even if patients experienced great improvement, their descriptions might have a dimension of doubt. Some devised "tests" to ascertain improvement, and some pondered whether any suspected improvement might be just the natural course of their illness or only their imagination. Some patients noticed dramatic improvement in their social relationships, negative emotions and behaviors or symptoms unrelated to IBS as biomedically defined.

\section{Outcomes: Idioms of Doubt}

The patients' knowledge that they might be receiving placebo treatment cast doubt on perceived improvements, and this was expressed in a number of different ways that turned on their past experience of the fluctuation of symptoms, the idea that those perceptions may have been due only to a change in their thinking and qualified any statement about possible improvement with markers of equivocation.

\section{"You Know it Fluctuates Anyways"}

Like the researchers themselves, the patients were concerned with distinguishing improvements that could have just been normal waxing and waning of their IBS from changes that were attributable to their treatments. Questions of causality were invoked to cast uncertainty and hesitancy over the attribution of perceived changes - even when they were dramatic. The vagaries of spontaneous amelioration created a moving benchmark that made unambiguous claims of improvement problematic.

Although Abigail experienced significant improvement, she still was concerned with attributing causality:

It's [IBS] been somewhat mitigated. I don't feel as bloated. I don't feel as constipated. I'm able to go to the bathroom a little bit easier.... And the IBS seems to have improved but who knows if it has anything to do with this acupuncture? It could be, you know, it fluctuates anyway.

Francis had similar concerns:

I have not been as constipated... I wanted to go to the bathroom and I said, "Hmm, I wonder if this is just a coincidence or what."

Ben, who originally complained of difficulty going out in public because bathrooms might not be nearby, later reported considerable improvement and stated that

I get out more, you know. But it's like that has a lot to do with the change in the weather, too. If the sun's out there, I can't stay in. 
"Maybe I'm Making the Whole Thing Up"

We have already described how patients were pervasively concerned that they might be receiving placebo treatment. Like the possibility of typical normal fluctuations in IBS symptoms, the knowledge that they might be receiving placebo treatment was cited to cast a cloud over the veracity of perceived improvement. At 3 weeks, Abigail ruminated:

Hmm. I think it's gotten progressively [better] a little but, again, I don't know ... it's hard to tell. Then I keep thinking, "Well maybe the treatment's aren't even real," so how do I know if it has anything to do with that?

Even with dramatic improvement at 6 weeks, Abigail continued to consider the possibility of a less than "genuine" recovery:

It makes you feel pretty stupid, I mean, because you think, "Oh, I seem to be getting better." Or, "Maybe I'm making the whole thing up." You know. I don't know.... You know, I just ... I feel much better, but who knows if it has anything whatever to do ... unless it's like a placebo effect like they say.

Deb expressed a similar predicament:

I mean, like, my gut-level feels like I'm in the right group, because there's been such a marked change, but again it could be [that], psychologically, I was just ready for this to happen ... you know, I could have made it happen on my own.

To avoid the potential of cognitive dissonance inherent in this situation, at the end of the trial, Alan preferred not to know whether or not he had been on placebo: "Well, it worked. You know. It worked. I mean ... if I wasn't [receiving genuine acupuncture], I don't know if I'd want to know."

\section{"I've Been Kind of Wondering"}

While both the "augmented" and the "limited" treatment arms expressed doubt in terms of natural fluctuations and the possibility of placebo treatment, an extra dimension of doubt seemed evident in the discourse of those patients who received a limited patient-practitioner interaction. Despite their measurable scores of improvement on the quantitative measures, especially at 3 weeks, there was a more hesitant communication. Perhaps this reflected the lack of a reinforcing patient-practitioner relationship that may have aided the consolidation of perceptions of change in the augmented arm. Often patients in the limited group prefaced or qualified their reports of change with expressions of uncertainty such as "I don't know" or "I think." Often patients, like Kate, seemed unsure: "I've been kind of wondering [about any changes]." Many of the responses in the limited arm had a "yes and no" quality, a back-and-forth style of hedging, as is noticeable in the three women quoted below, all describing their improvement at 3 weeks. 
Barbara recounted a shadowy improvement that was difficult to detect:

It's kind of like a very slow melting. Kind of like dry ice. I mean you see it but it's enough that you notice the difference. I mean it's not so insignificant that ... you know, you barely notice it. I mean you definitely notice it and you do see results. But not one hundred percent.

Relief is perceptible but sometimes remains subtle, as Francis explains:

I have not been as constipated. I have actually been going to the bathroom and I don't know if it's just a change in food, but I don't think so. Really, I don't change ... to a drastic degree.

Kate continued:

It's no cure. It definitely has not cured me of anything, but I think on a day-today basis, I'd say maybe there's an improvement in just general discomfort.

Such tentativeness is not altogether missing in the augmented group. For example, at 3 weeks, Emily says: "I'm not sure if that could be, but, uh, yeah the symptoms are, I mean ... currently, I feel a bit better than I felt.... It's hard to tell." At 6 weeks she became more emphatic.

\section{Outcomes: Idioms of Certainty}

Despite the shadow of limited expectations and worries about placebo treatment, many of our patients - in both placebo conditions-expressed a certainty in their perceptions of improvement. This definitiveness often turned on notions of "progression" or gradualism, or on references to self-described "tests" or experiments they had devised.

\section{"It's Been a Nice Progression"}

Deb, who was in the "limited" arm, reported steady improvement at 3 weeks and complete relief at the end of 6 weeks. At 3 weeks she said:

Like before I felt everything was just tight in there and compressed and um, now I just feel like it's kind of eased it a little bit.... It's been gradual, but consistent.... I started noticing that my stomach was kind of going down, and my stools kind of started changing. It's been a nice progression.

At 6 weeks she said, more definitely:

It's just great. I mean, I just continue to improve. I mean, I feel like I'm $99 \%$ better and ... I mean, everything [has improved]. All my original symptoms. I don't feel, um, all the bloating and the constipation. And just, you know, like I say most times stools have totally changed.

Similarly, Ben, who also had dramatic improvement in the "augmented" condition, provided another example: 
And then ... some point along the way, you realize, you know, you don't have diarrhea and you're not ... you say: "Wow, that's nice."

When improvement was steady it was invariably gradual. As Ben again observed:

It doesn't come on strong like, like an Imodium [a common antidiarrheal overthe-counter medicine]. [Imodium] kind of like affects you like in a rough way.... It [the RCT intervention] just kind of like smoothes in there and it just stops [the diarrhea]. And then some point along the way, you realize, you know, you don't have diarrhea.

Abigail, in the limited condition, also experienced steady incremental improvement: "I seemed to notice a change pretty soon. But I think it gradually got better even though I did notice something after one or two treatments."

Unlike the other patients, Alan, in the "augmented" arm, reported that his improvement meant he was less focused on his symptoms: "I think [the symptoms] had a steady improvement. I started noticing that throughout this process that I stopped thinking as much about my problems, because they weren't there as much."

\section{"I Want to See if this Works, You Know"}

For some patients, certainty as to whether they had benefited from treatment required actively testing or challenging their condition. They sometimes spoke as lay scientists for whom the outcomes of their tests constituted a particularly convincing idiom of certainty. Self-experimentation was meant to rescue certainty from doubt. For some patients this may have related to a high level of education. While patients in the study were allowed to continue on any medication regime that they had previously taken for at least a month prior to starting the trial, Ben spoke of discontinuing all his medications to test whether the treatment worked.

I know the doctor here told me, he says, "You can take whatever you have to take, you know, while you're on this [treatment protocol]. We don't care. You can take a medication while you're on this." But I can't see me wanting to take a medication if I'm on this. I want to see if this works, you know. I don't want to do anything else [while I'm in the study].

Kate also experimented:

I kind of put the acupuncture to the test, maybe two weeks ago or something and had a big meal with a lot of things that I probably shouldn't eat.

David also performed his own test:

I was prescribed an anti-spasmodic.... So two weeks before I started this acupuncture, I stopped. I made an executive decision. I said I'm not going to do this because I don't want to mask the acupuncture. 


\section{Outcomes: Dramatic Behavioral and Psychosocial Changes}

Patients most often described changes in the salient symptoms of IBS: pain, discomfort, bloating, diarrhea and constipation. Certainly in the quantitative RCT, patients were asked to rate these symptoms many times and in many different ways. In this qualitative study, subjects often also described specific changes in other areas as being especially important, including freedom from formerly necessary dietary restrictions, improvement in social relations, reduction in emotional distress and increase in positive affective states.

"I'm Not Afraid to Eat"

Diet and personal hygiene were important. Subjects spoke about becoming socially more "normal" and of the relief they felt as behaviors once routinely needed to maintain control over the body and to manage potentially stigmatizing flatulence or diarrhea fell away (cf. Goffman 1963).

Ben described his improvement this way: I'm not afraid to eat things, you know, like corn and stuff. I'm not afraid to eat. Like before I'd look at something and think, like, 'Hey, it might make me go [to the bathroom].' While Alan said, "I find myself eating foods that I haven't eaten in awhile or, you know, drinking caffeine if I want it because I don't have such severe attacks anymore." And, Kate: "I've eaten some foods that I would have thought would have triggered me off more [precipitate an IBS attack], some of the vegetables and chick peas and things like that usually give me a lot of trouble didn't seem quite so bad."

Abigail also noticed dietary changes:

Like usually I have to take Citrucel and I have to have a salad, a certain kind of salad, at night ... in order to go to the bathroom in the morning. Well I haven't been having the salad and I haven't been having the Citrucel and I've still been able to go to the bathroom.

David reported personal hygiene and telephone calls to be his yardstick for measuring change:

The urgency in the beginning was such that I would have minimal warning.

Now it's much more controlled. Now [I] have the luxury of saying, you know, I am going to go the bathroom [after lunch] but I'm going to make one more phone call.... Before [the study] it was men's room first, [the] phone call was definitely later.

\section{"I’ve Taken Steps to Leave My Husband"}

Our participants sometimes perceived their treatments precipitating positive changes in social relationships (including shifts in marital relationships), new emotional stability or other improvements not usually thought of as aspects of improvement in IBS. This occurred more often and more dramatically in the 
"augmented" group, where a psychosocial history was taken, but it also was present in the "limited" group, with reports of increased "emotional calmness."

For example, Greta had this to say about her marriage:

Well actually my husband and I are in the process of separating.... We [have] moved into different rooms in the same house. For me it's important to do that. The treatments ... reinforce me, [they] give me some energy to take the steps to [leave my husband].

Ben's change in marital relationship went in a different but still positive direction:

I'm calmer than I used to be. I know I don't yell as [much as I used to]. I was talking to my wife yesterday and I said, "I don't know. Maybe it is this. Maybe it is the acupuncture." I used to raise my voice and I used to yell a lot, when I talked to people ... and I find myself not doing that. And if [I] am doing it, I catch myself.

David felt renewed emotional stability and new moderation with alcohol:

And I feel that acupuncture, if nothing else ... has brought somewhat of a tranquility to my life. It's a very interesting, it's a very subtle change of how I feel about myself, and I've enjoyed it. There are times when I'm much generally more calm[er]. However, there are times when someone will do something that will aggravate me, and I'm not afraid to speak up to them and say how I feel.... [And] I cut down on my drinking, so I'm not waking up in the morning during the night. And so I'm sleeping better because the alcohol [drinking] has diminished.

\section{"[I] Feel Much More Optimistic About Life"}

Emotional improvement was often mentioned in the interviews. Abigail stated, "I'm sort of ... feeling more compassion for myself.... Well, it [the treatment] just makes me feel much more optimistic about life you know. You know, it makes me want to do stuff. Who wants to do stuff when they feel real crummy?" Sam, who otherwise had no improvement in irritable bowel complaints reported: "I think I'm less fearful, I get less anxious over things that are happening."

Importantly, all patients mentioned at some time during the interviews that, immediately after treatment, they, like Alan, felt "definitely calmer." Interestingly, many patients also reported that this feeling continued into their routine lives. Francis, who was in the limited group, reports: "It was just relaxing. I just found it very relaxing. Maybe that's because I don't usually lay down in the middle of the day. [Laughs.]"

Finally, other unexpected improvements occurred. As Ben reports: "I mean, you know. Like I ... I suffer from depression and ... I think this [treatment] might be helping with that ... [and] you might laugh. I feel I have a stronger sex drive." 


\section{Outcomes: Rhetoric of Alliance}

Some participants cast themselves as part of the research team. Kate, also in the limited arm, which discouraged talking, reported, "[I'm trying to stay as] uninformed as possible and not ask too many questions, I don't want to skew the data or something," while Ben, in the augmented interaction arm, worried, "The only thing that bothered me was I said, you know, 'What if I'm telling these poor people that I'm feeling better,' which I am, 'and they're giving me placebo. Doesn't this throw the whole thing off?' Doesn't it? You know! I think I was more worried about that than anything else!" David describes his absolute dedication to the trial:

[The acupuncturist] said to me, "Now, if you can't make a treatment, you know, you call us ... and we'll reschedule them." I thought, I mean, I would crawl to get there.... I can't imagine somebody being in a program and missing [an appointment].

Several of our patients explicitly worried about how the acupuncturist would feel if the trial did not succeed in proving that acupuncture worked. Some were particularly concerned that their accounts not harm the acupuncturists.

For example, Abigail pondered:

And recently the idea has popped into my head that, "Oh my G-d, what if they find out that it's not effective?"... That's, that is kind of scary. And then I felt bad for the acupuncturist, too. It would invalidate what she's doing. It must be hard for her. If I were her, I would be peeing in my pants. Oh my G-d. [Both she and interviewer laugh.]

Undoubtedly, this dedication to the trial and the concern for the practitioners also represent the importance of the close, dyadic bonding that occurred during the trial. In fact, all patients expressed confidence in, trust of and appreciation for their therapist, regardless of whether they were in the augmented or the limited arm.

\section{Discussion}

While our quantitative RCT recorded unambiguous aggregate "placebo effects" in IBS, in the embedded qualitative study, we found a response to placebo treatment that was more deliberative and complex. Perhaps such findings are inevitable when one examines the fine grain of actual experience. Improvement could mean a reduction in bodily dysphoria, changes in bowel movements, being able to eat foods that previously would have triggered severe symptoms, new emotional stability, or being able to go out in public more easily. For some patients, improvement was progressive and certain and included perceived dramatic psychosocial transformation. Others, primarily in the "limited" group, improvement seemed to be groping for what Csordas (2002) has called: "incremental and inconclusive effects that define the lowest threshold of efficacy." In both placebo treatment arms"augmented" and "limited"-even when patients felt completely relieved from their symptoms, there was rhetoric of hesitation and doubt. Some patients wondered 
whether their apparent improvement was actually due to natural history or to placebo effects. Some patients performed mini-experiments to test whether they were really better.

Our placebo treatment clearly was not some stand-alone, miraculous event, a deus ex machina, that dominated our patients' perceptions. For most, treatment was a new and uncertain perturbation of an already complex life-world. The treatments provided the patients with an opportunity to reorganize that world, and their improvements mirrored the multilevel, pervasive role of IBS in their daily lives. Ambiguity often prevailed; certainty of improvement could be difficult to sustain. Our patients struggled with such questions as: Was it the therapy or the salad that produced the improvement? Was it real therapy or dummy treatment? and Was my digestion better or worse a week ago? Separating the placebo input from other aspects of daily life was not easy. Their testimonies has what Bruner (1986) called the "indeterminacy of reality" and "the trafficking in human possibilities rather than in settled certainties."

The placebo response of each patient was an idiosyncratic, variable and unstable construction, undertaken in the novel context of an RCT composed of specialized and authoritative procedures (i.e., informed consent, the knowledge of randomization, the delivery of the treatment under conditions of "blinding," interrogation by social scientists). From the patient's viewpoint, the treatment they received was inherently ambiguous with regard to its potential to heal. From the researcher's point of view, that uncertainty was the raison d'être for the blinded clinical trial. Yet from the patients' side, the same carefully devised blend of doubt and concealment was a potent obstacle to the stability of any attempt to construe the treatment's effect on their illness. What we have highlighted here and sought to understand, however imperfectly, are their descriptions of those often inconclusive, selfcontradictory or vacillating attempts to cast the hints of "change" or "no change" into a convincing and stable account of how the treatments were affecting them. This "symbolic work" was interminable, not because of the obdurate nature of the patients' illness, but, at least for the duration of the trial, by design.

Our patients did not proceed from an initially determinate level of "expectation," along a regular slope of "response" or "nonresponse," to an "end-point" measure. Instead, embarking on treatment with an already complex and ambivalent attitude, they negotiated a variety of unpredictable trajectories using tactics that included intensified surveillance of their illnesses, psyches and social relations; "experiments" to test if they have "really changed"; equivocal and vacillating formulations; discourses of "expectation" and "hope;" certainty and uncertainty, as well as other maneuvers that we have undoubtedly failed to discern in our small sample - all in an attempt to construct a convincing, stable account of their response to treatments. In short, they traversed a turmoil of therapeutic uncertainty that was a direct consequence of the defining features of the RCT-placebos, informed consent, blinding — which made the "symbolic work" essentially unstable, shifting and protean (Lévi-Strauss 1963; Obeyesekere 1985, 1990).

Our findings challenge many of the dominant theories concerning placebo effects in RCTs, and encourage consideration of novel emergent views. Clearly, expectancy as conventionally understood does not provide a completely adequate account for 
our patients' testimony. Explicit positive expectations were mostly absent, and desperation was more typical. Many spontaneously expressed "hope," which they explicitly distinguished from "expectation." This finding corroborates two retrospective studies of patients who had previously participated in RCTs. Stone et al. (2004) interviewed nine participants from five different RCTs about their initial expectations. In this study, only one participant reported expectations of benefit, while the remaining eight distinguished clearly between hoping they would achieve some benefit and having any expectation of improvement. In another study, Di Blasi et al. (2005) performed 46 telephone interviews with patients who had completed a placebo-controlled pharmaceutical RCT for heel pain. While most (79\%) reported not having had "positive expectations" prior to receiving treatment, 52\% had "hoped" that the treatment would help. Other qualitative researchers have noted a similar caution in patients recruited to RCTs and, en passant, noted that individuals join trials with an attitude, to quote the patient's own words, of "Why not try it, just to see what it can do and if it can help good, great, but if it can't, we tried" (Conboy et al. 2008; cf. Paterson et al. 2008).

It is possible that some patients', denial of a "positive expectation" may have been partially determined as much by their concern to appear sophisticated with regard to this issue when being interviewed by a professional researcher as by any introspective discrimination between their own cognitive states. It is possible that these patients, who typically had already experienced multiple failed attempts at therapy for their IBS, may have consciously rejected or limited any expectation of benefit in order to avoid another disappointment. It is also possible that we are dealing with a disjunction between patients and researchers/clinicians regarding the meaning of "hope" and "expectation" (cf. Good-DelVecchio et al. 1990).

It would seem that some notion of a positive outcome figured in our patients' construction of "hope" - as they had, after all, undertaken an arduous effort to actively participate in an RCT involving a novel therapy. While they neither evinced "expectancy" of a positive outcome, in the probabilistic terms of clinical researchers, nor uncritically accepted the treatment as genuine, they may have negotiated the question of treatment effectiveness "not in the sense that their truth value is certified by logic or argument but in the sense that they are taken into the imagination and lived with, if only for a time" (Kirmayer 1993). Hope was a kind of passive volitional intention combined with imagination, will and acceptance. Hope was not so much a prediction as an existential stance: a lifejacket against despair.

The emergent neuroscience hypothesis of "prospection" provides another way of thinking about our findings concerning "expectation" and "hope." "Prospection" proposes that people constantly build "simulations" of the future in their minds to explore different future scenarios. This "multiplex theater" operates as a "stage" or "representational space whereby simulations of the future can be constructed and explored. A proposed detail of this constructional space is that it allows a representation of current reality and also secondary representations that explore future possibilities" (Buckner 2007). From this point of view, our patients are seen to have engaged in dynamic process that entertained multiple possibilities of the future (and even the present). Prospection allows for such multiple possibilities, which could include improvement, worsening and little change. Hope seems aligned 
to this notion of prospection and represents openness to multiple outcomes including amelioration.

Still another, more anthropological rubric for the examination of "expectation" and "hope" is the concept of "subjunctivity" of illness narratives, a concept that medical anthropology borrowed from the field of literary criticism (Bruner 1986; Kleinman 1988; Good 1994). In telling (or thinking) the story of their illnesses, especially chronic illnesses, individuals are often careful to indicate some uncertainty, if not frank hope, as to the anticipated future course. Theorists of ritual have noted that this subjunctive "as if" framework can actually pull someone into a deeper level of participation and somehow "make the illusion the reality" (Seligman et al. 2008). Closely related to this is the concept of "therapeutic narrative," which recognizes that the very process of clinical treatment inevitably involves the development, whether rudimentary or elaborate, of a projected narrative of how the patient will heal and that the patient's participation in treatment requires that the patient commits to some such projected story of "cure" or "recovery" or "rehabilitation," even if couched in the most tentative terms, that is, "hope" (Mattingly 1998). (Our team will report a more detailed analysis of the narrative features of these interviews elsewhere.)

Several of our patients attributed profound psychosocial transformations to their treatment, including improved marital relationships and emotional stability. Given the well-established importance of social stress in IBS (Drossman et al. 1999) and the recognition that psychosocial suffering is an important "idiom of distress" (Nichter 1981), placebo-induced improvement in this domain probably should not have been totally unexpected. It may be that improvement of IBS symptoms leads to more comfortable performance of expected social roles and reduces social impairment. An alternative explanation is suggested by reports of anthropologists who have found that users of alternative therapies see their healing as "embedded within and inseparable from a network of emotions and connectivity with others" (Barry 2006), and often report "whole-person effects that were characterized by changes in strength, and changes in personal and social identity" (Paterson and Britten 2003). Indeed, commentators have noted that alternative medicine's unusually broad self-defined scope of practice (e.g., "body, mind, and spirit" or "holistic") charts a similarly broad, even indeterminate, range of therapeutic targets (Kaptchuk 2002).

In view of the complexity of our patients' experiences, classical conditioning, like the expectancy model, also seems too simple in its formulation of the variables it takes into account as "paired stimulus" and "conditioned response." Our patients' accounts were often self-reflective and seemed to include a complex interplay of environmental clues and learning processes that included thought and imagery, as well as preconscious perceptual processes. For example, the perceived dramatic marital changes are difficult to account for in terms of conditioning. And, as with expectation, it is implausible that our patients' dismal history of failed medical treatment would have conditioned them to respond positively to the trial's placebo treatments, which were delivered in yet another recognizably medical environment. Also, on this score, all patients were naïve to acupuncture. 
The inadequacy of either conditioning or expectancy models to explain our findings suggests that recent phenomenological efforts to find a middle ground between the two poles of "reflective consciously accessible thought" and "reflex stimulus substitution" may be worth exploring for additional insights on placebo effects. Most notably, Frenkel (2008) has suggested that placebo treatment is less about cognitive representation of activity or reflection than it is "bodily engagement in the activity itself." The placebo is something experienced; it is as much something that happens as something that one thinks and believes. From this point of view, the individual's experience of response to a placebo is not only "cognitive" in the conventional academic sense, but also, and importantly, turns on a perceptual organization of bodily experience that occurs both prior to conscious thought and, also, as part of conscious thought. The invocations of hope we found in our interview data might be interpreted as an openness to experiencing what situations offer or, to use Gibbon's (1986) term, "afford." As Thompson et al. (2009) have recently suggested, the placebogenic environmental cues and learning processes are not necessary "solely, nor predominately, conscious" and involve "direct sensory, [affective] and embodied experience (or implicit perception)." For our patients, the experience of receiving a new therapy, even if tinged with doubt, provided a concrete opportunity for the reconstruction of "self" and "illness" in a novel context of "healing." To the extent that conscious mind is involved, it works according to Good's (1994) analysis, whereby: "Rather than [static] belief [or expectation] the focus is ... on interpretative activities ... [which allow events to be] confronted, [attended to,] experienced, elaborated [and confirmed]." Our patients attempted to construct a narrative from a series of events. Both "the immediate felt individual subjective" experience and the "conscious reflective grasping of this experience" were involved (Kapferer 1991).

Anxiety reduction could also be considered a salient aspect of the responses of our patients. Dramatically, without any prompting from the interviewer, all our participants said that their treatments made them feel "calmer" or "more relaxed." Patients told us that they "got less anxious over the things that were happening." It is possible that the sometimes-ambiguous signals of IBS are experienced and interpreted as less threatening, less alarming or more ordinary and uneventful because of less anxiety. The placebo altered participants' response criterion for what was pain, disruptive or worthy of attention (Allan and Siegel 2002). Also, with one exception, all patients claimed to scrutinize their symptoms more closely during the trial than before the trial. This is possibly due to the social support inherent in participating in a RCT that this self-examination took place with more detached interest, more curiosity, less dread and less anxiety than usual, which in turn may have led to generally lower levels of distress.

Other potential influences on our patients' accounts are worth considering. Report bias could have been a factor in some of the narratives of improvement. Obviously, we did not ask patients if their responses were intended to please the researchers. However, some patients expressed concern about how the outcome of the trial would affect the experimenters, and it is seems possible that report bias could have influenced their reports. 
Many of our patients' assessments turned critically on references to memory. In examining their interviews, we were struck, as other researchers have noted (e.g., Price et al. 1999), by how fragile this aspect of their interpretive process could be. While we cannot conclude that inaccuracy of memory helped to configure the placebo response of our patients, our study demonstrates a major role of retrospection in their accounts of symptom change, and raises questions as to the extent to which distortions of memory contribute to the subjective construction of treatment outcomes. Related to memory bias, and easily as important, attribution bias should also be mentioned as a potential contributor to magnitude of experienced positive outcomes. IBS fluctuates and, indeed, our patients often had difficult deciding whether their improvement was due to treatment or the natural course of their illness. Clearly conflating such unrelated changes with treatment outcomes could easily contribute to a more positive experience of treatment. (However, it should be noted, attribution bias cannot explain all of the positive changes because, as a group, patients treated with placebo did much better than those in the no treatment wait list controls in the parent RCT.)

Perhaps most importantly, all the potential mechanisms of placebo response we have already examined are unimaginable without the context of a patient-healer relationship (even if sometimes it was a "limited" one). Separating the cognitive, affective, physical and symbolic dimensions of this relationship from the earlierdiscussed mechanism seems impossible. All other factors seem to be intertwined and held together by the clinical encounter. Undoubtedly, the patient-healer interaction was a central aspect of this study (as it was in our earlier RCT), and was necessary to "trigger" the transformations our patient's experienced. Also, as mentioned earlier, in the parent RCT of this study, when the patient-practitioner relationship was systematically "augmented," our patients registered dramatically increased placebo responses. Its relevance to the placebo effect cannot be underestimated.

And finally, it is worth noting that the patient interaction in this RCT had more than the ordinary "activation" of a biomedical encounter. Solicitations for participants were widespread in the print, Internet and television media. Yet, enrolling was a challenge: patients were screened multiple times to insure they qualified. Many procedures such a randomization, blinding and informed consent were not routine. The RCT was both more intimate and more public. At three time points, 452 written questions that comprised the multiple batteries of questionnaires were administered. Nurses took vital signs and drew blood after each visit. And patients were aware that, in a de-identified form, every detail could eventually be published. The circumstances were extra-ordinary. And within the RCT, a second ritual of fake acupuncture added a further layer of "extra-ordinary."

To summarize our findings: Patients were realistic. They were aware that they might receive either placebo or genuine treatment. Their previous experiences with medical treatment were not positive and many had reached the point of despair. Motivated by "hope" and an openness to change, patients enacted their prescribed roles, in what Rappaport (1999), in his study of ritual, calls "more or less invariant sequences of formal acts and utterances not entirely encoded by the performer." In the charged atmosphere of the RCT that included intense questioning by research 
scientists and the possibility of novel treatment, most patient engaged in heightened self-scrutiny and reappraised their condition. The trial was accompanied by a constantly shifting assortment of embodied sensations including bodily feelings, symptoms, moods, laying on of hands, placebo needles, and blood tests and embodied behaviors including the abilities to make telephone calls and consume different foods. For almost all of our patients, through a process of self-surveillance, the placebo treatments were interpreted as engendering positive change, sometimes dramatically so. Yet, the cause of perceived amelioration was not necessarily obvious and was open to multiple attributions: new treatment, normal fluctuations in bodily sensations, shifts in behaviors or even placebo effects. Narratives were often provisional and included multiple and even contending perspectives. Ambiguity pervaded. No single theory of placebo response seems to explain the data. In this RCT, all proposed mechanisms could be see as embedded in the patient-healer relationship. For most patients, what began as an "as if" subjunctive interpretation of experience later became the premise for a construction of a healing encounter built on enactment, embodiment and interpretation-ultimately experienced as healing (cf. Rappaport 1999).

\section{Limitations}

Any inference from the results of our study about placebo treatment must be tempered by several limitations. First, our number of subjects was small, and this was only partially compensated for by the fact that the sample was randomly selected. The context of an acupuncture regime might not generalize to patients who undergo more familiar, conventional medication pill therapy (Kaptchuk and Eisenberg 1998). Besides having potentially expansive psychological dimensions (Barnes 1998), placebo acupuncture involves highly focused directed attention that is enveloped by unique kinds of apprehension, anxiety and trust (Liu 2008) and autonomic arousal (Park et al. 2008), more akin to what happens in a multisensory healing ritual than the more medical behavior of simply taking a pill (Kaptchuk et al. 2000) Furthermore, IBS is a complex disease and it is unclear whether the experiences of IBS patients generalize to other conditions. That said, it seems likely that the experiences reported in our research may apply to other conditions that are also defined in terms of patient reports of symptoms (e.g., chronic pain, depression or chronic fatigue syndrome).

An additional limitation is that our study relied on interviews conducted at a tertiary hospital research center and in the context of the social relationships engendered by an RCT. Patients almost certainly viewed their interviewers as knowing more about what they were undergoing than they did themselves, and could easily have pragmatically adjusted their statements to this context. That said, we do not know of any less biased, feasible method to obtain this type of data.

Finally, our study provides no data as to whether and to what extent our patients' responses to placebo treatment may be related to any of the biochemical, neuroendocrine or neuroanatomical correlates of the placebo effect that have been found in recent laboratory experiments. Also, given the absence of objective 
measures of outcome, placebo responses in this study could be mainly related to shifts in illness experiences due to selective attention to diffuse experiences. Our team anticipates further analyses of already gathered data to investigate such issues.

\section{Afterthought}

Some remarks on the RCT and ritual seem to be in order. The RCT claims to identify a mathematically precise demarcation between physiological causality and the effects of ritual. Clinical scientists developed it as a "rational," "skeptical" and objective apparatus to remove from medical knowledge the prejudicial taint of human "belief," "suggestion" and everyday subjectivity (Good 1994). Nonetheless, and perhaps inevitably, as has already been frequently observed, from an anthropological point of view, the RCT is a form of secular divination with its own rituals (Blumhagen 1979; Felker 1983; Kaptchuk and Kerr 2004; Kaptchuk et al. 2009). Importantly, the procedures of our particular RCT-conducted in the context of a large teaching hospital, with its placebo needles, white coats and community of practitioners and researchers, created its own version, of a ritual "cacophony of ... sight, touch and kinesthesia" (Desjarlais 1996), and of intense community involvement (Janzen 1976), that anthropologists have found to be characteristic of healing rituals "in the field." And yet, the placebo ritual is more than a biomedical-reduced version of the healing rituals found across cultures. It has a unique characteristic: the ritual of placebo treatment in an RCT embodies a deep suspiciousness of the ritual itself. Perhaps from the deliberate uncertainty inscribed in the informed consent, our patients shared and embodied the RCT's skepticism, doubt and tacit invitation for critical self-examination. It is understandable that they were concerned that their treatments might well lack real content and represent only the husk of appearance (Weber 1930; Seligman et al. 2008). The placebo ritual was presented within the context of the official, rational skepticism of biomedical research. It is even possible that the RCT's overwhelming serious skepticism infused the ritual with the culturally charged symbolic "power" of biomedicine. Yet despite the systematic infusion of doubt, or maybe precisely because of it, patients were still affected by the placebo treatment, and testified to the salubrious benefits of this most peculiar medical ritual.

Acknowledgments The research was made possible by Grant 1K24 AT004095 from the National Center for Complementary and Alternative Medicine (NCCAM), Grant 1R01 AT01414-01 from the NCCAM and the National Institutes of Digestive, Diabetes and Kidney Disease (NIDDK) and Grant 1R21 AT002860-01 from the NCCAM and the Office of Behavioral and Social Science Research (OBSSR). The research was also partially supported by a grant from the Samueli Institute for Information Biology. The contents of this report are solely the responsibility of the authors and do not necessarily represent the official views of the National Institutes of Health (NIH). Also, this research was supported in part by Grant RR 01032 to the Beth Israel Deaconess Medical Center (BIDMC) General Clinical Research Center from the NIH. We thank Irving Kirsch, Roger Davis, Mary Quilty, Andrea Rivers and Franklin Miller for feedback on the manuscript and help during the study, and Jackie Craigue for editorial assistance. We also thank Byron Good, Mary-Jo DelVecchio Good, Daniel Moerman and Arthur Kleinman for their intellectual and administrative support and inspiration. 
Open Access This article is distributed under the terms of the Creative Commons Attribution Noncommercial License which permits any noncommercial use, distribution, and reproduction in any medium, provided the original author(s) and source are credited.

\section{References}

Adler, H.M., and V.B.O. Hammett

1973 The Doctor-Patient Relationship Revisited: An Analysis of the Placebo Effect. Ann Intern Med 78: 595-598.

Ader, R.

1997 The Role of Conditioning in Pharmacotherapy. In The Placebo Effect: An Interdisciplinary Exploration. A. Harrington, ed. Cambridge, MA: Harvard University Press.

Allan, L.G., and S. Siegel

2002 A Signal Detection Theory Analysis of the Placebo Effect. Eval Health Prof 25: 410-420.

Amanzio, M., and F. Benedetti

1999 Neuropharmacological Dissection of Placebo Analgesia: Expectation-activated Opioid Systems versus Conditioning-activated Specific Subsystems. J Neurosci 19: 484-494.

Barnes, L.

1998 The Psychologizing of Chinese Healing Practices in the United States. Cult Med Psych 22: 413-443.

Barry, C.A.

2006 The Role of Evidence in Alternative Medicine: Contrasting Biomedical and Anthropological Approaches. Soc Sci Med 62: 2646-2657.

Benedetti, F.

2008 Mechanism of Placebo and Placebo-related Effects Across Diseases and Treatments. Annu Rev Pharm Tox 48: 33-60.

2009 Placebo Effects. New York: Oxford University Press.

Benedetti, F., H.S. Mayberg, T.D. Wager, C.S. Stohler, and J.K. Zubieta

2005 Neurobiological Mechanism of the Placebo Effect. J Neurosci 25: 10390-10402.

Benedetti, F., M. Amanzio, S. Vighetti, and G. Asteggiano

2006 The Biochemical and Neuroendocrine Bases of the Hyperalgesic Nocebo Effect. J Neurosci 26: 12014-12022.

Blumhagen, D.W.

1979 The Doctor's White Coat. The Image of the Physician in Modern America. Ann Intern Med 9: 111-116.

Botha, C., and G. Libby

2006 Irritable Bowel Syndrome: Anxiety in Gastroenterology. Br J Hosp Med 67: 344-349.

Brody, $\mathrm{H}$.

1997 The Doctor as Therapeutic Agent. In The Placebo Effect: An Interdisciplinary Exploration. A. Harrington, ed. Cambridge, MA: Harvard University Press.

Bruner, J.

1986 Actual Minds, Possible Worlds. Cambridge, MA: Harvard University Press.

Buckner, R.L.

2007 Prospection and the Brain. Behav Brain Sci 30: 318-319.

Cleophas, T.J.M.

1995 The Importance of Placebo Effects. JAMA 1995: 273-283.

Colloca, L., M. Sigaudo, and F. Benedetti

2008 The Role of Learning in Nocebo and Placebo Effects. Pain 136: 211-218.

Comaroff, J.

1976 A Bitter Pill to Swallow: Placebo Therapy in General Practice. Sociol Rev 24: 79-96.

Conboy, L.A., R.H. Wasserman, E.E. Jacobson, R.B. Davis, A.T.R. Legedza, M. Park, A. Rivers, E.B.

Morey, B.H. Nam, L. Lasagna, I. Kirsch, A.J. Lembo, T.J. Kaptchuk, and C.E. Kerr

2006 Investigating Placebo Effects in Irritable Bowel Syndrome: A Novel Research Design. Cont Clin Trials 27: 123-134. 
Conboy, L., M.T. Quilty, C.K. Kerr, J. Shaw, and P. Wayne

2008 A Qualitative Analysis of Adolescents' Experiences of Active and Sham Japanese-style Acupuncture Protocols Administered in a Clinical Trial. J Altern Comp Med 14: 699-705.

Crowne, D.P., and D. Marlowe

1960 A New Scale of Social Desirability Independent of Psychopathology. J Consult Psych 24: 349.

Csordas, T.H.

1994 The Sacred Self: A Cultural Phenomenology of Charismatic Healing. Berkeley: University of California Press.

Csordas, T.J.

2002 Body/Meaning/Healing. New York: Palgrave.

Desjarlais, R.R.

1996 Presence. In The Performance of Healing. C. Laderman and M. Roseman, eds. New York: Routledge.

Di Blasi, Z., E. Harness, E. Ernst, A. Georgiou, and J. Kleijnen

2001 Influence of Context Effects on Health Outcomes: A Systematic Review. Lancet 357: 757-762.

Di Blasi, Z., F. Crawford, C. Bradley, and J. Kleijnen

2005 Reactions to Treatment Debriefing among Participants of a Placebo Controlled Trial. BMC Health Serv Res 5: 30.

Dow, J.

1986 Universal Aspects of Symbolic Healing: A Theoretical Synthesis. Am Anthropol 88: 56-69.

Drossman, D.A., F.H. Creed, K.W. Olden, J. Svedlund, B.B. Toner, and W.E. Whitehead

1999 Psychosocial Aspects of the Functional Gastrointestinal Disorders. Gut 45: 1125-1130.

Enck, P., F. Benedetti, and M. Schedlowski

2008 New Insights into the Placebo and Nocebo Responses. Neuron 59: 195-206.

Eisenberg, L.

1977 Disease and Illness. Cult Med Psychiatry 1: 9-23.

1983 The Subjective in Medicine. Perspect Biol Med 27: 48-61.

Evans, F.J.

1974 The Placebo Response in Pain Reduction. Adv Neurol 74: 289-296.

Felker, M.E.

1983 Ideology and Order in the Operating Room. In The Anthropology of Medicine: From Culture to Method. L. Romanucci-Ross, D.E. Moerman, and L.R. Tancredi, eds. New York: Praeger.

Frank, J.

1961 Persuasion and Healing. Baltimore: Johns Hopkins Press.

Frenkel, O.

2008 A Phenomenology of the 'Placebo Effect': Taking Meaning from the Mind and the Body. J Med Philos 33: 58-79.

Furmark, T., L. Appel, S. Henningsson, F. Abs, V. Faria, C. Linnman, A. Pissiota, O. Frans, M. Bani,

P. Bettidca, E.M. Pich, E. Jacobsson, K. Wahlstedt, L. Oreland, B. Langstrom, E. Eriksson, and

M. Fredrikson

2008 A Link between Serotonin-related Gene Polymorphisms, Amygdala Activity, and Placeboinduced Relief of Social Anxiety. J Neurosci 28: 12066-12074.

Geers, A.L., P.E. Weiland, K. Kosbab, S.J. Landry, and S.G. Helfer

2005 Goal Activation, Expectations, and the Placebo Effect. J Pers Soc Psychol 89: 141-159.

Geers, A.L., S.G. Helfer, P.E. Weiland, and K. Kosbab

2006 Expectations and Placebo Response: A Laboratory Investigation into the Role of Somatic Focus. J Behav Med 29: 171-178.

Gibson, J.J.

1986 The Ecological Approach to Visual Perception. Hillsdale, NJ: Lawrence Erlbaum Associates.

Goffman, E.

1963 Stigma: Notes on the Management of Spoiled Identity. Englewood Cliffs, NJ: Spectrum/Prentice Hall.

Good, B.J.

1994 Medicine, Rationality and Experience. Cambridge, UK: Cambridge University Press.

Good-DelVecchio, M.J., L. Hunt, C. Schaffer, and S.E. Lind

1990 American Oncology and the Discourse on Hope. Cult Med Psychiatry 14: 59-79. 
Hahn, R., and A.M. Kleinman

1983 Belief as Pathogen, Belief as Medicine: "Voodoo Death" in Anthropological Perspective. Med Anthropol Q 14(3): 16-19.

Hróbjartson, A., and P.C. Gotzsche

2001 Is the Placebo Powerless? An Analysis of Clinical Trials Comparing Placebo with No Treatment. N Engl J Med 344: 1594-1602.

Janzen, J.M.

1976 The Quest for Therapy: Medical Pluralism in Lower Zaire. Berkeley: University of California Press.

Kamper, S.J., A.C. Machado, R.D. Herbert, C.G. Maher, and J.H. McAuley

2008 Trial Methodology and Patient Characteristics Do Not Influence the Size of Placebo Effects on Pain. Meta-regression of Trial-level Factors. J Clin Epidemiol 61: 255-260.

Kapferer, B.

1991 A Celebration of Demons: Exorcism and the Aesthetics of Healing in Sri Lanka. Washington, DC: Smithsonian Institution Press.

Kaptchuk, T.J.

1998a Intentional Ignorance: A History of Blind Assessment and Placebo Controls. Bull Hist Med 72: $389-433$.

1998b Powerful Placebo: The Dark Side of the Randomized Controlled Trial. Lancet 351: 1722-1725.

2002 The Placebo Effect in Alternative Medicine: Can the Performance of a Healing Ritual Have Clinical Significance? Ann Intern Med 136: 817-825.

2003 Effect of Interpretive Bias on Research Evidence. BMJ 326: 1458-1465.

2008 An Audience with Ted Kaptchuk. Nat Drug Discov 7: 554.

Kaptchuk, T.J., and D.M. Eisenberg

1998 The Persuasive Appeal of Alternative Medicine. Ann Intern Med 129: 1061-1065.

Kaptchuk, T.J., and C.E. Kerr

2004 Unbiased Divination, Unbiased Evidence, and the Patulin Clinical Trial. Int J Epidemiol 33: 247-251.

Kaptchuk, T.J., P. Goldman, D.A. Stone, and W.B. Stason

2000 Do medical Devices Have Enhanced Placebo Effects? J Clin Epidemiol 53: 786-792.

Kaptchuk, T.J., W.B. Stason, R.B. Davis, A.T.R. Legedza, R.N. Schnyer, C.E. Kerr, D.A. Stone, B.H.

Nam, I. Kirsch, and R.H. Goldman

2006 Sham Device versus Inert Pill: Randomized Controlled Trial of Two Placebo Treatments. BMJ 332: 391-397.

Kaptchuk, T.J., J.M. Kelley, L.A. Conboy, R.B. Davis, C.E. Kerr, E.E. Jacobson, I. Kirsch, R.N. Schyner, B.Y. Nam, L.T. Nguyen, M. Park, A.L. Rivers, C. McManus, E. Kokkotou, D.A. Drossman, P. Goldman, and A.J. Lembo

2008 Components of the Placebo Effect: A Randomized Controlled Trial in Irritable Bowel Syndrome. BMJ 336: 999-1003.

Kaptchuk, T.J., C.E. Kerr, and A. Zanger

2009 Placebo Controls, Exorcisms and the Devil. Lancet (in press).

Kelley, J.M., A.J. Lembo, J.S. Ablon, J.J. Villanueva, L.A. Conboy, R. Levy, C.D. Marci, C. Kerr,

I. Kirsch, E.E. Jacobson, H. Riess, and T.J. Kaptchuk

2009 Patient and practitioner influences on the placebo effect in irritable bowel syndrome. Psychosom Med (in press).

Kirmayer, L.J.

1993 Healing and the Invention of Metaphor: The Effectiveness of Symbols Revisited. Cult Med Psychiatry 17: 161-195.

Kirsch, I.

1985 Response Expectancy as a Determinant of Experience and Behavior. Am Psych 40: 1189-1202.

1997 Specifying Nonspecifics: Psychological Mechanisms of Placebo Effects. In The Placebo Effect. An Interdisciplinary Exploration. A. Harrington, ed. Cambridge, MA: Harvard University Press.

2004 Conditioning, Expectancy, and the Placebo Effect: Comment on Steward-Williams and Podd. Psychol Bull 130(2): 341-342.

Kleinman, A.

1973 Medicine's Symbolic Reality. On a Central Problem in the Philosophy of Medicine. Inquiry 16: 206-213. 
1988 The Illness Narratives. Suffering, Healing, and the Human Condition. New York: Basic Books. Klinger, R., S. Soost, H. Flor, and M. Worm

2007 Classical Conditioning and Expectancy in Placebo Hyperalgesia: A Randomized Controlled Study in Patients with Atopic Dermatitis and Persons with Health Skin. Pain 128: 31-39.

Knight, L.J., H.E. Barbaree, and F.J. Boland

1986 Alcohol and the Balanced-placebo Design: the Role of Experimenter Demands in Expectancy. J Abnorm Psychol 35: 335.

Kong, J., R.L. Gollub, I.S. Rosman, J.M. Webb, M.G. Vangel, I. Kirsch, and T.J. Kaptchuk

2006 Brain Activity Associated with Expectancy-enhanced Placebo Analgesia as Measured by Functional Magnetic Resonance Imaging. J Neurosci 26: 381-388.

Kong, J., T.J. Kaptchuk, G. Polich, I. Kirsch, and R.L. Gollub

2007 Placebo Analgesia: Findings from Imaging Studies and Emerging Hypotheses. Rev Neurosci 18: 173-190.

Kong, J., R.L. Gollub, G. Polich, I. Kirsch, P. LaVioette, M. Vangel, B. Rosen, and T.J. Kaptchuk

2008 An fMRI Study on the Neural Mechanisms of Hyperalgesic Nocebo Effect. J Neurosci 28: 13354-13362.

Lembo, A.J., L. Conboy, J.M. Kelley, R.S. Schnyer, M. McManus, M.T. Quilty, C.E. Kerr, E.E. Jacobson, R.B. Davis, and T.J. Kaptchuk

2009 A Treatment Trial of Acupuncture for IBS Patients. Am J Gastroenterol (in press).

Lévi-Strauss, C.

1963 The Sorcerer and his Magic, and the Effectiveness of Symbols, in Structural Anthropology. New York: Basic Books.

Liu, T.

2008 Acupuncture: What Underlies Needle Administration? eCAM 2008: 1-9.

Longstreth, G.F., W.G. Thompson, W.D. Chey, L.A. Houghton, F. Mearin, and R.C. Spiller 2006 Functional Bowel Disorders. Gastroenterology 130: 1480-1491.

Lundh, L.G.

1987 Placebo, Belief and Health: A Cognitive-emotional Model. Scand J Psychol 28: 128-143.

Lydiard, R.B.

2001 Irritable Bowel Syndrome, Anxiety, and Depression: What are the Links? J Clin Psych 62: $38-45$

Mattingly, C.

1998 Healing Dramas and Clinical Plots: The Narrative Structure of Experience. Cambridge: Cambridge University Press.

McGlashan, T.H., F.J. Evans, and M.T. Orne

1969 Nature of Hypnotic Analgesia and Placebo Response to Experimental Pain. Psychosom Med 31(3): 227-246.

Moerman, D.E.

1979 The Anthropology of Symbolic Healing. Curr Anthropol 10(1): 59-80.

Moerman, D.

2002 Meaning, Medicine and the 'Placebo Effect'. Cambridge, UK: Cambridge University Press.

Moerman, D.R., and W.B. Jonas

2002 Deconstructing the Placebo Effect and Finding the Meaning Response. Ann Intern Med 136: $471-476$

Nichter, $M$.

1981 Idioms of Distress: Alternatives in the Expression of Psychosocial Distress; A Case Study from South India. Cult Med Psychiatry 5: 379-408.

Obeyesekere, G.

1985 Depression, Buddhism and the Work or Culture in Sri Lanka. In Culture and Depression. A. Kleinman and B. Good, eds. Berkeley: University of California.

1990 The Work of Culture. Chicago: University of Chicago Press.

Orne, M.T.

1962 On the Social Psychology of the Psychological Experiment. Am Psych 17: 776-783.

Pacheoco-Lopez, G., H. Engler, M.B. Niemi, and M. Schedlowski

2006 Expectations and Associations that Heal: Immunomodulatory Placebo Effects and Its Neurobiology. Brain Behav Immun 20: 430-436. 
Park, K., J. Lee, J.C. Kwon, W. Choi, S. Lee, and V. Napadow

2008 Multi-organ Autonomic Responses to Verum and Phantom Acupuncture. Society for Neuroscience Annual Meeting, Washington, DC, November, abstract no. 266.2/EE24.

Patel, S.M., W.B. Stason, A. Legedza, S.M. Ock, T.J. Kaptchuk, L. Conboy, K. Canenguez, J.B. Park, E.

Kelly, E. Jacobson, C.E. Kerr, and A.J. Lembo

2005 The Placebo Effect in Irritable Bowel Trials: A Meta-analysis. Neurogastroenterol Motil 17: 332-340.

Paterson, C., and N. Britten

2003 Acupuncture for People with Chronic Illness: Combining Qualitative and Quantitative Outcomes Assessments. J Altern Complement Med 9: 671-681.

Paterson, C., Z. Zheng, C. Xue, and Y. Wang

2008 "Playing their Parts": The Experiences of Participants in a Randomized Sham-controlled Acupuncture Trial. J Altern Complement Med 14(2): 199-208.

Petrovic, P., E. Kalso, K.M. Petersson, and M. Ingvar

2002 Placebo and Opioid Analgesia - Imaging a Shared Neuronal Network. Science 284: 1737-1740.

Petrovic, P., T. Dietrich, P. Frannsso, J. Andersson, and K.I. Carlsson

2005 Placebo in Emotional Processing-induced Expectations of Anxiety Relief Activated a Generalized Modulatory Network. Neuron 46: 957-969.

Price, D.D., and L.V. Soerensen

2002 Endogenous Opioid and Non-opioid Pathways as Mediators of Placebo Analgesia. In The Science of the Placebo. H.A. Guess, A. Kleinman, J.W. Kusek, and L.W. Engel, eds. London: BMJ Books.

Price, D.D., L.S. Milling, I. Kirsch, A. Duff, G.H. Montgomery, and S.S. Nicholls

1999 An Analysis of Factors that Contribute to the Magnitude of Placebo Analgesia in an Experimental Paradigm. Pain 83: 147-156.

Rainville, P., J.C. Doucet, M.C. Fortin, and G.H. Duncan

2004 Rapid Deterioration of Pain Sensory-discriminative Information in Short-term Memory. Pain 110: 605-615.

Rappaport, Roy A.

1999 Ritual and Religion in the Making of Humanity. Cambridge: Cambridge University Press.

Rawlins, M.D.

1990 Development of a Rational Practice of Therapeutics. BMJ 301: 729-733.

Scott, D.J., C.S. Stohler, C.M. Egnatuk, H. Wang, R.A. Koeppe, and J.K. Zubieta

2007 Individual Differences in Reward Responding Explain Placebo-induced Expectations and Effects. Neuron 55: 325-336.

Shapiro, A.K., V. Mike, H. Barten, and E. Shapiro

1973 Study of the Placebo Effect with a Self-administered Placebo Test. Compr Psychiatry 14: 535-548.

Seligman, A.B., R.P. Weller, M.J. Puett, and B. Simon

2008 Ritual and Its Consequences. New York: Oxford University Press.

Staats, P.S., A. Staats, and H. Hekmat

2001 The Additive Impact of Anxiety and a Placebo on Pain. Pain Med 2: 267-279.

Steward-Williams, S., and J. Podd

2004 The Placebo Effect: Dissolving the Expectancy versus Conditioning Debate. Psychol Bull 130(2): 324-340.

Stewart, M.A.

1995 Effective Physician-patient Communication and Health Outcomes: A Review. Can Med Assoc J 152: $1423-1433$.

Stone, D.A., C.E. Kerr, E. Jacobson, L.A. Conboy, and T.J. Kaptchuk

2004 Patient Expectations in Placebo-controlled Randomized Clinical Trials. J Eval Clin Pract 11: 77-84.

Streitberger, K., and J. Kleinhenz

1998 Introducing a Placebo Needle into Acupuncture Research. Lancet 352: 364-365.

Sullivan, M.D.

1993 Placebo Controls and Epistemic Control in Orthodox Medicine. J Med Philos 18: 213-231.

Tambiah, S.J.

1977 The Cosmological and Performative Significance of a Thai Cult of Healing Through Meditation. Cult Med Psych 1: 97-132. 
1985 The Cosmological and Performative Significance of a Thai Cult of Healing Through Meditation and A Performative Approach to Ritual. In Culture Thought and Social Action. Cambridge, MA: Harvard University Press.

1990 Magic, Science, Religion, and the Scope of Rationality. Cambridge, MA: Cambridge University Press.

Thompson, J.J., C. Ritenbaugh, and M. Nichter

2009 Reconsidering the Placebo Response from a Broad Anthropological Perspective. Cult Med Psychiatry 33(1): 112-152.

Turkkan, J.S.

1989 Classical Conditioning: The New Hegemony. Behav Brain Sci 12: 121-179.

Turner, V.

1967 The Forest of Symbols. Aspects of Ndembu Ritual. Ithaca, NY: Cornell University Press.

Vase, L., M.E. Robinson, G.N. Verne, and D.D. Price

2005 Increased Placebo Analgesia Over Time in Irritable Bowel Syndrome (IBS) Patients is Associated with Desire and Expectation but Not Endogenous Opioid Mechanisms. Pain 115: $338-347$.

Weber, M.

1930 The Protestant Ethic and the Spirit of Capitalism. New York: Charles Scribner's Son.

Zubieta, J.K., J.A. Bueller, L.R. Jackson, D.J. Scott, Y. Xu, R.A. Koeppe, T.E. Nichols, and C.S. Stohler 2005 Placebo Effects Mediated by Endogenous Opioid Activity on u-opioid Receptors. J Neurosci 25 : 7754-7762. 